\title{
The Evolution of COVID-19: A Minimal Invasive Autopsy Cohort Studying in Depth the Different COVID- 19 Disease Stages
}

Valentino D'Onofrio
Hasselt University

\section{Lotte Keulen}

Antwerp University Hospital

Annelore Vandendriessche

Antwerp University Hospital

Jasperina Dubois

Jessa Hospital

Reinoud Cartuyvels

Jessa Hospital

Marie-Elena Vanden Abeele

Jessa Hospital

Judith Fraussen

Hasselt University

Patrick Vandormael

Hasselt University

Veerle Somers

Hasselt University

Ruth Achten

Jessa Hospital

Amélie Dendooven

Antwerp University Hospital

Ann Driessen

Antwerp University Hospital

Lukasz Augsburg

Jessa Hospital

Niels Hellings

Hasselt University

Martin Lammens

Antwerp University Hospital

Jan Vanrusselt 
Jessa Hospital

Janneke Cox( $\sim$ janneke.cox@jessazh.be )

Hasselt University

\section{Research Article}

Keywords: Minimal invasive autopsy, COVID-19 disease stages, histopathology, radiology, immunology, microbiology

Posted Date: August 26th, 2021

DOl: https://doi.org/10.21203/rs.3.rs-765012/v1

License: (9) This work is licensed under a Creative Commons Attribution 4.0 International License. Read Full License 


\section{Abstract}

\section{Background}

The WHO defines different COVID-19 disease stages, where pathophysiological mechanisms differ. Clinical, radiological, histological, microbiological, and immunological characteristics of different COVID-19 disease stages were evaluated.

\section{Methods}

Forty-four PCR-confirmed COVID-19 patients were included in a prospective minimal invasive autopsy cohort. Patients were classified according to WHO disease classification in mild-moderate $(n=4)$, severe-critical $(n=32)$ and post-acute disease $(n=8)$ and clinical, radiological, histological, microbiological, and immunological data were compared.

\section{Results}

Classified according to Thoracic Society of America, patients with mild-moderate disease had no typical COVID-19 images on CT-Thorax versus $71.9 \%$ with typical images in severe-critical disease and $87.5 \%$ typical images in post-acute disease $(p<.001)$. Diffuse alveolar damage was absent in mildmoderate disease but present in $93.8 \%$ and $87.5 \%$ of patients with severe-critical and post-acute COVID19 , respectively $(p=.002)$. Other organs with histopathological changes were liver and heart. Interferong levels were significantly higher in patients with severe-critical COVID-19. Overall, $72 \%$ of patients had positive anti-SARS CoV-2 IgM and 51\% positive lgG.

\section{Conclusion}

Significant differences in pathological and immunological characteristics between patients with mildmoderate disease compared to patients with severe-critical disease were found, whereas differences between patients with severe-critical disease and post-acute disease were limited. This emphasizes the need for tailored treatment of COVID-19 patients.

\section{Introduction}

Since the first report in December 2019 of patients infected with severe acute respiratory syndrome corona virus 2 (SARS CoV-2), this virus has travelled the globe. Coronavirus disease (COVID-19) has caused tremendous mortality and morbidity worldwide and continues to do so ${ }^{1}$.

SARS CoV-2 infection is characterized by different disease stages. After primary infection, patients may either remain asymptomatic, or develop symptoms including fever, fatigue, cough, myalgia, loss of smell or gastro-intestinal complaints, so called mild disease. This can progress to moderate disease, in which the lower respiratory tract becomes infected and develops into severe respiratory disease and critical disease leading to respiratory failure, multi-organ failure and death ${ }^{2}$. Moreover, in some patients 
surviving COVID-19, post-acute COVID-19 syndrome occurs, with persistent and prolonged effects on multiple organ systems ${ }^{3}$. Typically, COVID-19 incubation period is 5 days (range 1-14 days), with progression to severe disease 8 days after disease onset (range 7-14 days) and to critical disease after 16 days (range 12-20 days) ${ }^{3}$. Post-acute COVID-19 syndrome is considered as a disease duration of longer than 4 weeks after symptom onset. Approximately $20 \%$ of the symptomatic patients evolve towards severe or critical disease ${ }^{4}$. Approximately $17-35 \%$ of the hospitalized COVID-19 patients require treatment in the intensive care unit (ICU) whereof $20 \%$ die. However, these proportions vary depending on infection demographics, thresholds for hospitalization, and availability of ICU beds ${ }^{1,5}$. Post COVID-19 sequelae are reported in $32-87 \%$ of patients ${ }^{6,7}$.

The main underlying pathophysiological mechanisms are proposed to be different in different disease stages. Early in the disease course, direct cellular toxicity due to viral replication is believed to be the main driver of pathology, while the progression towards clinically more severe disease is related to a complex dysregulation of the immunological response leading to a hyperinflammatory state including hypercoagulability ${ }^{8,9}$. Moreover, due to prolonged (ICU) admission, patients are at risk for hospitalrelated complications, including secondary infections and treatment toxicity. The pathophysiology of

post-acute COVID-19 syndrome remains unclear, but potentially includes virus-specific changes of cells, inflammatory damage after acute infection and post-critical illness ${ }^{3}$. A clear understanding of the pathophysiology during the different disease stages provides important information for the development of treatment strategies ${ }^{8}$.

We have set up a prospective observational minimal invasive autopsy (MIA) cohort of patients that died with COVID-19. In this paper we report the clinical, histological, radiological, microbiological, and immunological characteristics at different COVID-19 disease stages including patients with post-acute COVID-19.

\section{Results}

\section{Patient characteristics}

A flowchart is provided in Fig. 1. In total, 87 eligible patients died in the Jessa Hospital during the study period, family members of 75 patients were contacted and $48(64.0 \%)$ patients were included, for whom the characteristics are shown in Table 1. The median time from death to MIA was 17h50min (10h5420h58). Forty-four (91.7\%) patients were PCR confirmed SARS-CoV-2 positive during illness, and four (8.3\%) patients were radiologically confirmed. 
Table 1

Characteristics of included patients.

\begin{tabular}{|c|c|c|c|c|}
\hline & $\begin{array}{l}\text { Total } \\
(n= \\
44)\end{array}$ & $\begin{array}{l}\text { Mild/Moderate } \\
\text { Disease } \\
(n=4)\end{array}$ & $\begin{array}{l}\text { Severe/Critical } \\
\text { Disease } \\
(n=32)\end{array}$ & $\begin{array}{l}\text { Post-Acute } \\
\text { Disease }(n=8)\end{array}$ \\
\hline Age (years, median (IQR) & $\begin{array}{l}82 \\
(73- \\
86)\end{array}$ & $84(69-87)$ & $83(75-88)$ & $75(69-84)$ \\
\hline Sex (female, n (\%)) & $\begin{array}{l}19 \\
(43.2)\end{array}$ & $2(50.0)$ & $15(46.9)$ & $2(25.0)$ \\
\hline Charlson Comorbidity Index (a) & $\begin{array}{l}2(1- \\
4)\end{array}$ & $3(2-5)$ & $2(1-4)$ & $2(2-4)$ \\
\hline $\begin{array}{l}\text { Duration of symptoms (days, median } \\
(\text { IQR)) }\end{array}$ & $\begin{array}{l}12 \\
(7- \\
19)\end{array}$ & $2(1.5-2.5)$ & $11(6-14)$ & $32(29-46)$ \\
\hline $\begin{array}{l}\text { Time between positive PCR and } \\
\text { death (days, median (IQR)) }\end{array}$ & $\begin{array}{l}10 \\
(4- \\
19)\end{array}$ & $4(2-8)$ & $8(4-14)$ & $29(26-39)$ \\
\hline LOS (days, median (IQR)) & $\begin{array}{l}11 \\
(4- \\
22)\end{array}$ & $10(3-18)$ & $8(3-19)$ & $23(23-26)$ \\
\hline \multicolumn{5}{|l|}{ Treatment restrictions (b) } \\
\hline COVID AA & $\begin{array}{l}12 \\
(27.3)\end{array}$ & $1(25.0)$ & $6(18.7)$ & $5(62.5)$ \\
\hline COVID A & $\begin{array}{l}10 \\
(22.7)\end{array}$ & $0(0.0)$ & $9(28.1)$ & $1(12.5)$ \\
\hline COVID B & $\begin{array}{l}21 \\
(47.7)\end{array}$ & $2(50.0)$ & $17(53.1)$ & $2(25.0)$ \\
\hline COVID C & $\begin{array}{l}1 \\
(2.3)\end{array}$ & $1(25.0)$ & $0(0.0)$ & $0(0.0)$ \\
\hline \multicolumn{5}{|l|}{ Respiratory support at death (all) } \\
\hline None & $\begin{array}{l}2 \\
(4.5)\end{array}$ & $2(50.0)$ & $0(0.0)$ & $0(0.0)$ \\
\hline $\begin{array}{l}\text { To a maximum } 15 \mathrm{~L} \mathrm{O}_{2} \text { on non- } \\
\text { rebreathing mask }\end{array}$ & $\begin{array}{l}22 \\
(50.0)\end{array}$ & $2(50.0)$ & $18(56.3)$ & $2(25.0)$ \\
\hline
\end{tabular}

Values are presented as number (\%) except where indicated otherwise. (a): Charlson Comorbidity Index: not age corrected; (b): COVID AAA: no restrictions, including extra-corporal membrane oxygenation (ECMO), COVID AA: allowed invasive oxygen therapy, not ECMO, COVID A: allowed ICU admission, not invasive oxygen therapy, COVID B: maximal treatment without ICU admission, COVID C: comfort therapy; (c): $n=5$ missing; Symptom onset was unknown in 8 patients, disease duration starting from a positive nasopharyngeal PCR was used; LOS: Length of Stay; IQR: interquartile range. 


\begin{tabular}{|c|c|c|c|c|}
\hline & $\begin{array}{l}\text { Total } \\
(n= \\
44)\end{array}$ & $\begin{array}{l}\text { Mild/Moderate } \\
\text { Disease } \\
(n=4)\end{array}$ & $\begin{array}{l}\text { Severe/Critical } \\
\text { Disease } \\
(n=32)\end{array}$ & $\begin{array}{l}\text { Post-Acute } \\
\text { Disease }(n=8)\end{array}$ \\
\hline High flow $\mathrm{O}_{2}$-therapy & $\begin{array}{l}11 \\
(25.0)\end{array}$ & $0(0.0)$ & $9(28.1)$ & $2(25.0)$ \\
\hline Invasive & $\begin{array}{l}9 \\
(20.5)\end{array}$ & $0(0.0)$ & 5 (15.6) & $4(50.0)$ \\
\hline Dexamethasone treatment & $\begin{array}{l}17 \\
(40.5)\end{array}$ & $1(25.0)$ & $14(45.2)$ & $2(25.0)$ \\
\hline Remdesivir treatment (c) & $\begin{array}{l}1 \\
(2.3)\end{array}$ & $0(0.0)$ & $0(0.0)$ & $1(12.5)$ \\
\hline $\begin{array}{l}\text { Anticoagulation treatment in the last } \\
2 \text { days before death }\end{array}$ & $\begin{array}{l}33 \\
(76.7)\end{array}$ & $1(25.0)$ & $25(80.6)$ & 7 (87.5) \\
\hline $\begin{array}{l}\text { Antibiotic treatment in the last } 2 \text { days } \\
\text { before death }\end{array}$ & $\begin{array}{l}20 \\
(45.5)\end{array}$ & $0(0.0)$ & $17(53.1)$ & $3(37.5)$ \\
\hline \multicolumn{5}{|c|}{$\begin{array}{l}\text { Values are presented as number (\%) except where indicated otherwise. (a): Charlson Comorbidity } \\
\text { Index: not age corrected; (b): COVID AAA: no restrictions, including extra-corporal membrane } \\
\text { oxygenation (ECMO), COVID AA: allowed invasive oxygen therapy, not ECMO, COVID A: allowed ICU } \\
\text { admission, not invasive oxygen therapy, COVID B: maximal treatment without ICU admission, COVID } \\
\text { C: comfort therapy; (c): } n=5 \text { missing; Symptom onset was unknown in } 8 \text { patients, disease duration } \\
\text { starting from a positive nasopharyngeal PCR was used; LOS: Length of Stay; IQR: interquartile range. }\end{array}$} \\
\hline
\end{tabular}

In none of the four patients with radiologically confirmed COVID-19 we found evidence of SARS CoV-2 infection: post-mortem SARS-CoV-2 PCR on lung tissue and serological testing for SARS CoV-2 antibodies at death were negative for all four patients. Time since symptom onset was 1, 6, 11, and 27 days, respectively. Heart failure $(n=1)$ and bacterial pneumonia $(n=1)$ were defined as alternative cause of death (COD) in two patients. The remaining two patients were classified as viral pneumonia of unknown origin as histology showed signs of viral pneumonia, but additional PCR for non-SARS CoV-2 viral and atypical bacterial respiratory pathogens was negative. As COVID-19 was not confirmed in any of these cases, they were excluded from further analyses.

Four out of $44(9.1 \%)$ patients had mild-moderate disease according to the WHO definition with a median (IQR) disease duration of 2 days (1.5-2.5d) (Table 1). Most patients had severe-critical disease $(n=32$, 72.7\%) with a median (IQR) disease duration of 11 days (6-14d) and all had respiratory support at death: a maximum of $15 \mathrm{~L} \mathrm{O}_{2}$ in $18(56.3 \%)$ patients, high-flow oxygen therapy in nine (28.1\%) patients and invasive ventilation in five (15.6\%) patients. Eight out of 44 (18.2\%) patients had post-acute COVID-19, i.e. a symptom onset longer than 28 days before death. The median (IQR) disease duration was 32 days (29$46 \mathrm{~d})$. All eight patients had critical disease during their disease course. At death four patients $(50.0 \%)$ were on invasive ventilation, two $(25.0 \%)$ on high-flow oxygen therapy and two $(25.0 \%)$ on a maximum of $15 \mathrm{~L} \mathrm{O}_{2}$. 


\section{Radiological findings}

A detailed description of the CT findings of thorax, abdomen and cerebrum is listed in supplementary Table 1. Five out of $36(14 \%)$ patients showed clinically relevant abnormalities on CT-cerebrum and 8 $(18.2 \%)$ on the CT-abdomen. There were no significant differences in frequency of abnormalities between disease stage.

Comparing the CT-thorax images according to Thoracic Society of America classification revealed significant differences between disease stages. There were no typical images in patients with mildmoderate disease, which was significantly different from patients with severe-critical disease $(n=23$, $71.9 \%)$ and patients with post-acute disease $(n=7,87.5 \% ; p=0.003)$ (Table 2). Although there was no difference in the number of patients with ground glass opacities (GGO) between disease stages, the location and distribution of GGO differed significantly: all (100\%) patients with severe-critical or postacute disease had bilateral GGO, while this was $50 \%$ in patients with mild or moderate disease $(p<.001)$. All patients with mild-moderate disease had a peripheral distribution of GGO while respectively $70.4 \%$ and $50.0 \%$ of patients with severe-critical disease and post-acute disease had a diffuse distribution ( $p$ $=.0005)$. In addition, there were no patients with mild-moderate disease with crazy paving, which was significantly different from other disease stages $(p=.014)$. Fibrosis was seen only twice, once in mildmoderate disease and once in post-acute disease, but the latter was pre-existent. 
Table 2

Computer tomography findings of the thorax

\begin{tabular}{|c|c|c|c|c|}
\hline & $\begin{array}{l}\text { Total } \\
(n= \\
44)\end{array}$ & $\begin{array}{l}\text { Mild/Moderate } \\
\text { disease } \\
(n=4)\end{array}$ & $\begin{array}{l}\text { Severe/Critical } \\
\text { disease } \\
(n=32)\end{array}$ & $\begin{array}{l}\text { Post-acute } \\
\text { disease } \\
(n=8)\end{array}$ \\
\hline \multicolumn{5}{|l|}{ COVID-19 pneumonia (a) } \\
\hline No COVID-19 pneumonia & $2(4.5)$ & $1(25.0)$ & $0(0.0)$ & $1(12.5)$ \\
\hline $\begin{array}{l}\text { Atypical COVID-19 } \\
\text { pneumonia }\end{array}$ & $\begin{array}{l}8 \\
(18.2)\end{array}$ & $3(75.0)$ & $5(15.6)$ & $0(0.0)$ \\
\hline $\begin{array}{l}\text { Indeterminate COVID-19 } \\
\text { pneumonia }\end{array}$ & $4(9.1)$ & $0(0.0)$ & $4(12.5)$ & $0(0.0)$ \\
\hline $\begin{array}{l}\text { Typical COVID-19 } \\
\text { pneumonia }\end{array}$ & $\begin{array}{l}30 \\
(68.2)\end{array}$ & $0(0.0)$ & $23(71.9)$ & 7 (87.5) \\
\hline \multicolumn{5}{|l|}{ Overall severity } \\
\hline Mild & $\begin{array}{l}7 \\
(15.9)\end{array}$ & $2(50.0)$ & $4(12.5)$ & $1(12.5)$ \\
\hline Moderate & $\begin{array}{l}11 \\
(25.0)\end{array}$ & $2(50.0)$ & $8(25.0)$ & $1(12.5)$ \\
\hline Severe & $\begin{array}{l}26 \\
(59.1)\end{array}$ & $0(0.0)$ & $20(62.5)$ & $6(75.0)$ \\
\hline \multicolumn{5}{|c|}{ COVID-19 suspected findings } \\
\hline Ground glass opacities & $\begin{array}{l}37 \\
(84.1)\end{array}$ & $2(50.0)$ & $27(84.4)$ & $8(100.0)$ \\
\hline Crazy Paving & $\begin{array}{l}29 \\
(65.9)\end{array}$ & $0(0.0)$ & $23(71.9)$ & $6(75.0)$ \\
\hline Consolidations & $\begin{array}{l}39 \\
(88.6)\end{array}$ & $3(75.0)$ & $29(90.6)$ & 7 (87.5) \\
\hline Organizing pneumonia & $1(2.3)$ & $0(0.0)$ & $0(0.0)$ & $1(12.5)$ \\
\hline Fibrosis & $2(4.5)$ & $1(25.0)$ & $0(0.0)$ & $1(12.5)$ \\
\hline
\end{tabular}

\section{Histopathological findings}

The most prominent histopathological abnormalities were found in the lungs (Table 3). Other organs with significant changes were liver and heart (Table 4). No COVID-related abnormalities were found in the kidney, spleen, or abdominal fat. All histopathological findings are displayed in supplementary Table 2. 
Page $9 / 26$ 
Table 3

Main histological changes in the lungs

\begin{tabular}{|c|c|c|c|c|}
\hline & $\begin{array}{l}\text { Total } \\
(n= \\
44)\end{array}$ & $\begin{array}{l}\text { Mild/Moderate } \\
\text { disease }(n=4)\end{array}$ & $\begin{array}{l}\text { Severe/critical } \\
\text { disease }(n=32)\end{array}$ & $\begin{array}{l}\text { Post-acute } \\
\text { disease }(n=8)\end{array}$ \\
\hline ARDS/DAD & $\begin{array}{l}37 \\
(84.1)\end{array}$ & $0(0.0)$ & $30(93.8)$ & 7 (87.5) \\
\hline Early exudative phase & $\begin{array}{l}25 \\
(67.8)\end{array}$ & $0(0.0)$ & $23(76.7)$ & $2(25.0)$ \\
\hline Mid proliferative phase & $\begin{array}{l}10 \\
(27.0)\end{array}$ & $0(0.0)$ & $6(20.0)$ & $4(50.0)$ \\
\hline $\begin{array}{l}\text { Late/organizing fibrotic } \\
\text { phase }\end{array}$ & $\begin{array}{l}2 \\
(5.4)\end{array}$ & $0(0.0)$ & $1(3.3)$ & $1(12.5)$ \\
\hline \multicolumn{5}{|l|}{$\begin{array}{l}\text { Fibrin deposition/Hyaline } \\
\text { membranes }\end{array}$} \\
\hline None/absent & $\begin{array}{l}7 \\
(15.9)\end{array}$ & $3(75.0)$ & $3(9.4)$ & $1(12.5)$ \\
\hline Mild & $\begin{array}{l}7 \\
(15.9)\end{array}$ & $1(25.0)$ & $4(12.5)$ & $2(25.0)$ \\
\hline Moderate & $\begin{array}{l}18 \\
(40.9)\end{array}$ & $0(0.0)$ & $16(50.0)$ & $2(25.0)$ \\
\hline Severe & $\begin{array}{l}12 \\
(27.3)\end{array}$ & $0(0.0)$ & $9(28.1)$ & $3(37.5)$ \\
\hline Fibrosis & $\begin{array}{l}26 \\
(59.1)\end{array}$ & $0(0.0)$ & $21(65.6)$ & $5(62.5)$ \\
\hline \multicolumn{5}{|l|}{ Lymfocytic infiltrate } \\
\hline None/scarse & $\begin{array}{l}0 \\
(0.0)\end{array}$ & $0(0.0)$ & $0(0.0)$ & $0(0.0)$ \\
\hline Few & $\begin{array}{l}6 \\
(13.6)\end{array}$ & $2(50.0)$ & $3(9.4)$ & $1(12.5)$ \\
\hline Moderate amount & $\begin{array}{l}27 \\
(61.4)\end{array}$ & $2(50.0)$ & $19(59.4)$ & $6(75.0)$ \\
\hline Numerous & $\begin{array}{l}11 \\
(25.0)\end{array}$ & $0(0.0)$ & 10 (31.3) & $1(12.5)$ \\
\hline \multicolumn{5}{|l|}{ Macrophages } \\
\hline None/scarse & $\begin{array}{l}0 \\
(0.0)\end{array}$ & $0(0.0)$ & $0(0.0)$ & $0(0.0)$ \\
\hline
\end{tabular}

Values are presented as number (\%) except where indicated otherwise. 


\begin{tabular}{|c|c|c|c|c|}
\hline & $\begin{array}{l}\text { Total } \\
(n= \\
44)\end{array}$ & $\begin{array}{l}\text { Mild/Moderate } \\
\text { disease }(n=4)\end{array}$ & $\begin{array}{l}\text { Severe/critical } \\
\text { disease }(n=32)\end{array}$ & $\begin{array}{l}\text { Post-acute } \\
\text { disease }(n=8)\end{array}$ \\
\hline Few & $\begin{array}{l}8 \\
(18.2)\end{array}$ & $3(75.0)$ & $3(9.4)$ & $2(25.0)$ \\
\hline Moderate amount & $\begin{array}{l}23 \\
(52.3)\end{array}$ & $0(0.0)$ & $20(62.5)$ & $3(27.5)$ \\
\hline Numerous & $\begin{array}{l}13 \\
(29.5)\end{array}$ & $1(25.0)$ & $9(28.1)$ & $3(37.5)$ \\
\hline Thrombi & $\begin{array}{l}1 \\
(2.3)\end{array}$ & $0(0.0)$ & $1(3.2)$ & $0(0.0)$ \\
\hline Pneumocyte atypia & $\begin{array}{l}32 \\
(72.3)\end{array}$ & $1(25.0)$ & $26(81.3)$ & $6(75.0)$ \\
\hline \multicolumn{5}{|l|}{ Megakaryocytes } \\
\hline None & $\begin{array}{l}19 \\
(43.2)\end{array}$ & $1(25.0)$ & $13(41.9)$ & $5(62.5)$ \\
\hline One & $\begin{array}{l}5 \\
(11.4)\end{array}$ & $1(25.0)$ & $3(9.4)$ & $1(12.5)$ \\
\hline Two or more & $\begin{array}{l}20 \\
(45.5)\end{array}$ & $2(50.0)$ & $16(50.0)$ & $2(25.0)$ \\
\hline Vasculitis & $\begin{array}{l}3 \\
(6.8)\end{array}$ & $0(0.0)$ & $1(3.2)$ & $2(25.0)$ \\
\hline
\end{tabular}


Table 4

Main histological changes in the heart and liver

\begin{tabular}{|c|c|c|c|c|}
\hline Liver & $\begin{array}{l}\text { Total } \\
(\mathrm{n}= \\
44)\end{array}$ & $\begin{array}{l}\text { Mild/Moderate } \\
\text { disease }(n=4)\end{array}$ & $\begin{array}{l}\text { Severe/critical disease } \\
(n=32)\end{array}$ & $\begin{array}{l}\text { Post-acute disease } \\
(n=8)\end{array}$ \\
\hline \multicolumn{5}{|l|}{ Sinus dilatation } \\
\hline Absent or mild & $\begin{array}{l}16 \\
(36.4)\end{array}$ & $1(25.0)$ & $9(28.1)$ & $6(75.0)$ \\
\hline Moderate & $\begin{array}{l}20 \\
(45.5)\end{array}$ & $3(75.0)$ & $16(50.0)$ & $1(12.5)$ \\
\hline Severe & $\begin{array}{l}8 \\
(18.2)\end{array}$ & $0(0.0)$ & 7 (21.9) & $1(12.5)$ \\
\hline \multicolumn{5}{|l|}{$\begin{array}{l}\text { Lobular } \\
\text { inflammation }\end{array}$} \\
\hline None/absent & $\begin{array}{l}33 \\
(75.0)\end{array}$ & $3(75.0)$ & $27(84.4)$ & 3 (37.5) \\
\hline Mild & $\begin{array}{l}9 \\
(20.5)\end{array}$ & $1(25.0)$ & $4(12.5)$ & $4(50.0)$ \\
\hline Moderate & $\begin{array}{l}0 \\
(0.0)\end{array}$ & $0(0.0)$ & $0(0.0)$ & $0(0.0)$ \\
\hline $\begin{array}{l}\text { Severe with } \\
\text { necrosis }\end{array}$ & $\begin{array}{l}2 \\
(4.5)\end{array}$ & $0(0.0)$ & $1(3.1)$ & $1(12.5)$ \\
\hline Heart & $\begin{array}{l}\text { Total } \\
(n= \\
42)\end{array}$ & $\begin{array}{l}\text { Mild/Moderate } \\
\text { disease }(n=4)\end{array}$ & $\begin{array}{l}\text { Severe/critical disease } \\
(n=30)\end{array}$ & $\begin{array}{l}\text { Post-acute disease } \\
(n=8)\end{array}$ \\
\hline \multicolumn{5}{|l|}{ Fibrosis } \\
\hline None/absent & $\begin{array}{l}20 \\
(47.6)\end{array}$ & $3(75.0)$ & $15(50.0)$ & $2(25.0)$ \\
\hline Mild & $\begin{array}{l}13 \\
(31.0)\end{array}$ & $1(25.0)$ & $9(30.0)$ & 3 (37.5) \\
\hline Moderate & $\begin{array}{l}4 \\
(9.5)\end{array}$ & $0(0.0)$ & $2(6.7)$ & $2(25.0)$ \\
\hline Severe & $\begin{array}{l}5 \\
(11.9)\end{array}$ & $0(0.0)$ & $4(13.3)$ & $1(12.5)$ \\
\hline $\begin{array}{l}\text { Acute } \\
\text { myocarditis }\end{array}$ & $\begin{array}{l}1 \\
(2.4)\end{array}$ & $0(0.0)$ & $0(0.0)$ & $1(12.5)$ \\
\hline
\end{tabular}




\section{Lung}

Diffuse alveolar damage (DAD) was absent in patients with mild-moderate disease, while present in $93.8 \%$ and $87.5 \%$ of patients with severe-critical or post-acute COVID-19 respectively $(p=.002)$. Moreover, we mainly saw early exudative DAD in severe-critical COVID-19, where mid proliferative phase was most prevalent in post-acute disease, while late organizing DAD was virtually absent in both groups. Hyaline membranes were absent in patients with mild-moderate disease, while present in $81.3 \%$ of patients with severe-critical COVID-19 and $62.5 \%$ of patients with post-acute COVID-19 $(p=.019)$. Pneumocyte atypia was more prevalent in severe-critical disease $(81.3 \%)$ and post-acute disease $(75 \%)$ than in mild-moderate disease (25.0\%) (n.s.). Acute neutrophilic inflammation compatible with bacterial pneumonia was present in all groups. Overall, we rarely saw vasculitis (3/44) and thrombi (1/44). The composition of inflammatory infiltrates differed mainly between the mild-moderate group and the other groups. Moderate to numerous macrophages were present in $90.6 \%$ of patients with severe-critical disease and in $75 \%$ with post-acute disease, compared to $25.0 \%$ of patients with mild-moderate disease $(p=.042)$ and the presence of lymphocytes was most prominent in patients with severe-critical (90.6\%) and post-acute $(87.5 \%)$ disease compared to patients with mild-moderate disease $(50.0 \%)(p=.024)$. The lymphocytic infiltrates consisted mainly of CD3 + T-lymphocytes. In only two patients a discordance between lymphocytic infiltrate and CD3 expression was found (4.5\%) where the lymphocytic infiltrates were scored as moderate, while CD3 + cells were scored as scarce. Microscopic fibrosis (deposition of collagen and accumulation of fibroblasts) was seen in none of the patients with mild-moderate disease, while this was present in $65.6 \%$ of patients with severe-critical disease and only $62.5 \%$ of patients with post-acute COVID (n.s.).

\section{Liver}

The most important finding in all liver biopsies was prominent dilation of the sinusoids, without significant differences between disease stages. The presence of lobular inflammation was, in contrast, limited to a few patients and mostly mild or moderate.

\section{Heart}

Biopsies of the heart were obtained in 42 patients. Histological findings were similar in all three groups. Nineteen patients presented with moderate to severe fibrosis of cardiac tissue (21.4\%), indicating underlying long-standing cardiovascular disease. Acute myocarditis was found in only one patient (2.3\%) with post-acute COVID-19 disease. In three patients, circulating neutrophils were found in cardiac capillaries, but not enough evidence of interstitial inflammation was seen $(7.1 \%)$.

\section{Microbiological findings}

Cultures on post-mortem lung tissue revealed 22 pathogens in 17/44 (38.6\%) patients, mainly gramnegative bacteria $(15 / 22,68.1 \%)$ (Supplementary Table 3$)$. Three $(75.0 \%)$ patients with mild-moderate disease, 11 (34.4\%) patients with severe-critical disease and three (37.5\%) patients with post-acute COVID-19 had positive cultures with relevant pathogens (n.s.). When correlated to clinical, radiological, 
and histological findings, $13(29.5 \%)$ patients had a bacterial or fungal infection as the COD or contributing diagnosis, two (50\%) with mild-moderate disease, nine (28\%) with severe-critical disease and two $(25 \%)$ with post-acute COVID-19.

\section{Immunological findings}

Median concentrations of 13 cytokines in plasma of deceased patients collected post-mortem are shown per disease stage in Fig. 2. Interferon- $y$ (IFNY) levels were significantly higher in patients with severecritical disease $(p=.046)$. Although there were no other significant differences in cytokine levels, a trend was observed for higher levels of interleukin 6 (IL-6), IFNy-induced protein 10 (IP-10) and granulocyte macrophage colony stimulating factor (GM-CSF) and lower levels of interferon-a (IFNa) in patients with severe-critical disease. Dexamethasone treatment was not associated with cytokine levels.

None of the included patients were vaccinated against COVID-19. Overall, $31 / 43$ (72\%, 1 missing sample) patients were seropositive for anti-SARS CoV-2 antibodies of the IgM isotype, while 22/43 (51\%) were positive for IgG. Two (66\%) patients with mild-moderate disease, 22 (68.8\%) patients with severe-critical disease and seven (87.5\%) patients with post-acute disease had anti-SARS-CoV-2 IgM antibodies, and two (66\%), 13 (40.6\%) and seven (87.5\%) had anti-SARS-CoV-2 IgG antibodies, respectively.

Disease duration was not significantly different between patients with a positive and a negative IgM response $(p=.362)$. Of the $21 \mathrm{lgG}$ negative patients, $17(81 \%)$ had a disease duration of $\leq 12$ days. The four IgG negative patients with a disease duration of $>12$ days could be considered immunosuppressed with underlying B-cell lymphoma $(n=1)$, hemodialysis $(n=1)$, amyloidosis $(n=1)$, and non-Hodgkin lymphoma with immunosuppressive medication, including rituximab and high dosage steroids $(n=1)$.

Comparison of anti-SARS-CoV-2 IgG levels according to the NIBSC standard, to a cutoff value associated with 6-month protection from infection ${ }^{10}$ showed that oonly $12 / 43(28 \%)$ had sufficiently high anti-SARSCoV-2 lgG levels.

When correlating cytokine levels with antibody positivity, no significant differences were found, but a trend towards higher IP-10 levels in patients with negative $\lg M$ antibodies was observed $(p=.054)$.

\section{Cause of Death}

The COD and all contributing diagnoses are shown in Fig. 3 and supplementary Table 4 . The number of patients with severe-critical disease that died of COVID-19 pneumonia (59.4\%) was greater than that of patients with mild-moderate disease $(0 \%)$ and patients with post-acute disease $(37.5 \%)$, although this difference was not significant $(p=.06)$.

In patients with mild-moderate disease, the COD was heart failure $(n=1,25 \%)$, small cell lung carcinoma $(n=1,25 \%)$, multi-organ failure due to small intestine ischemia $(n=1,25 \%)$, and hemorrhagic and semirecent ischemic cerebrovascular accident $(n=1,25 \%)$. The COD in patients with severe-critical disease was COVID-19 severe pneumonia in 19 (59.4\%) patients, heart failure in four (12.5\%), bacterial pneumonia in two (6.3\%), intracerebral bleeding in two (6.3\%), and sepsis, massive pulmonary embolism, 
severe COPD, and multi-organ failure due to rhabdomyolysis each in one (3.1\%) patient. The COD in one patient was unknown. The COD in patients with post-acute disease were COVID-19 severe pneumonia ( $\mathrm{n}$ $=3,37.5 \%)$, heart failure $(n=1,12.5 \%)$, sepsis $(n=1,12.5 \%)$, sudden death of unknown origin $(n=1$, $12.5 \%)$, crescentic glomerulonephritis $(n=1,12.5 \%)$, and paratracheal bleeding $(n=1,12.5 \%)$.

\section{Discussion}

This prospective observational MIA cohort in patients with COVID-19 describes the clinical, radiological, histopathological, microbiological, and immunological differences between different disease stages. Patients with mild-moderate disease had fewer abnormalities on CT, did not show DAD in lung biopsies and had a less pronounced cytokine response compared to patients with severe-critical disease. However, differences between patients with severe-critical disease and post-acute disease were rather limited. Radiology showed equally high prevalence of crazy paving and bilateral consolidation. Histologically, DAD was present equally in both groups with $>60 \%$ of patients with post-acute COVID-19 in early exudative or mid proliferative stage. Immunologically, no significant differences in cytokine responses, except IFNy, were seen.

In none of the four radiologically confirmed COVID-19 patients we could confirm post-mortem the diagnosis of COVID-19 infection, despite elaborate investigations. This emphasises the need to reconsider the diagnosis of COVID-19 if the molecular confirmation in lacking, and to optimize the diagnostic strategy for both COVID-19 and alternative diagnoses.

Furthermore, despite having a disease onset of $>28$ days, most patients with post-acute COVID-19 had a radiological, histological, and immunological profile of acute respiratory distress syndrome. One may postulate that patients included in this cohort i.e., hospitalized patients that died, had an aberrant disease course that did not show a dampening of the acute lung damage and failed to progress to a more chronic phase ${ }^{11,12}$. Even in patients with the longest disease duration ( $>32$ days) no trend toward chronic disease was observed. This confirms the idea of acute inflammation as an important cause of mortality 13,14 . Although groups are small, this may have important implications for treatment of these patients, as they may benefit, even at such a long disease duration, from (prolonged) treatments like those given to patients with severe-critical disease.

A remarkable finding was the difference in composition of the inflammatory infiltrate, with macrophages still being present in a relatively high percentage in the post-acute disease. Macrophages play an important and dual pro- and anti-inflammatory role in ARDS. Literature suggests that the M1 type is present in earlier phases, releasing pro-inflammatory cytokines, while the M2 type is present in later phases to eliminate apoptotic cells, thereby possibly contributing to fibrosis ${ }^{15}$. Histopathological fibrosis was seen in a high percentage of patients with severe-critical and post-acute disease. It must be noted that not all patients with fibrosis showed typical DAD features. Some patients showed mild to moderate fibrosis thought to be pre-existent, without any other signs of DAD. 
Next, megakaryocytes were easily found in a large proportion of patients. It has been reported that an increased number of pulmonary megakaryocytes, responsible for production of platelets, can be seen in lung tissue of COVID-19 patients with DAD. This is thought to underline the relation with embolic/thrombotic events reported in COVID-19 patients ${ }^{16}$. Nevertheless, a low number of thrombi and vasculitis were seen in this cohort, much lower than commonly reported in the literature ${ }^{17,18}$. One possible reason is that we performed MIA instead of full autopsies and obtained tissue cores of approximately $5 \times 30 \mathrm{~mm}$, which has a higher chance of 'sampling error', especially to catch relatively large structures like thrombi and larger vessels.

We found profound abnormalities in the lungs and liver, but no distinctive COVID-related findings were found in the other organs that were investigated. In other autopsy series, various abnormalities were described in virtually all organs. However, in these studies, complete autopsies were performed with more extensive tissue sampling and higher yield ${ }^{12,19}$. We collected per protocol lung biopsies from radiological abnormal and normal tissue, however "radiologically normal" lung tissue was limited, and disease involvement of all lobes was most frequent. This was confirmed histologically as biopsies labelled "radiologically normal" had only in 3/44 (6.8\%) cases no or few abnormalities.

No significant differences in cytokine responses, except IFNy, were found between disease stages. However, IP-10, IL-6, and GM-CSF levels tended to be higher in patients with severe-critical disease compared to mild-moderate disease. These are pro-inflammatory cytokines, typically seen during cytokine storm and related to hyperinflammation-induced severe disease. Histopathological findings in the lung could support this hypothesis: lymphocytes and plasma cells were more prominent in patients with severe-critical disease.

Moreover, a trend towards decreased cytokine levels was seen in post-acute COVID-19. Even though this decrease did not return to levels as low as during mild-moderate disease, this, together with the finding that macrophages and T-lymphocytes were seen more prominently in the lung during severe-critical disease, could point to an increased immune response followed by a start to return to normal. Patients with post-acute COVID-19 did not have leukopenia shortly before death, and therefore this observation cannot be explained by immune exhaustion.

Of course, these interpretations should be assessed with caution because of small groups, differences were not significant, and cytokines were measured in plasma which is not necessarily representative of findings in the lung. Furthermore, this is a cohort of the most ill patients. We do not know if these findings truly reflect COVID-19 or reflect other complications during their disease.

IFNa levels tended to be higher in patients with mild-moderate disease. IFNa is a type I interferon and has been shown to be an important anti-viral response cytokine related to COVID-19 severity. An impaired IFN type I response was previously reported to be present in patients that developed critical disease 20 . Moreover, patients with inborn errors in type I IFN are at risk of developing life-threatening COVID-19 ${ }^{21}$. In addition, the observed trend for higher IP-10 levels in IgM negative patients points toward an impaired 
immune response. Our findings could indicate that mild disease patients but not patients with severecritical or post-acute disease, had an adequate antiviral response and therefore did not develop typical COVID-19 pneumonia and may have died of other causes than the virus or hyperinflammation.

Almost $30 \%$ of our patients had a bacterial pneumonia, which is higher than the $14 \%$ co- or sur-infection rate in mixed wards/ICU settings reported in the literature ${ }^{22}$. This may be explained by selection bias, i.e., the most severely ill patients were included in this cohort. Nevertheless, restricted antibiotic use should be propagated from an antimicrobial stewardship perspective.

Our study has limitations. Although MIA is a good alternative to conventional autopsies, tissue sample size is relatively small, which limits a good overview of all architectural abnormalities that might be present and increase sampling error. Also, certain crucial organs like the brain have not been sampled. Moreover, during (ICU) admission, patients generally develop multiple problems, leading to organ damage and changes in inflammatory response. It is therefore impossible to disentangle what abnormalities have been caused by SARS CoV-2 and what not.

In conclusion, we found that patients that die during different COVID-19 disease stages show certain distinct clinical, radiological, pathological, and immunological features. Patients with mild-moderate disease showed relatively few pathological abnormalities with a probable adequate immune response and did not die of but with COVID-19. Patients with severe-critical disease showed extensive pulmonary abnormalities, typically reflecting an overreactive and distorted immune response, and mostly died because of COVID-19 pneumonia. Lastly, patients with post-acute disease, despite some trends towards a dampened immunological response, mostly have similar clinical, radiological, and histopathological features compared to severe-critical disease.

The study of pathophysiological changes during different disease stages remains important to elucidate the mechanisms of this new disease. The distinct features during different disease stages show that a tailored and personal management of COVID-19 patients is necessary.

\section{Methods}

Study Design and patients

This study is a prospective cohort. A subset of our cohort has been described in a previous publication ${ }^{23}$. All patients that died during hospitalization with polymerase chain reaction (PCR) or radiologically confirmed COVID-19 were eligible for inclusion. Radiologically confirmed COVID-19 was defined as a person in whom PCR testing for COVID-19 is negative, but in whom the diagnosis is made on the basis of a suggestive clinical presentation and a compatible CT-scan ${ }^{24}$. Inclusion took place during working hours (9 am to 5 pm), 7 days per week from 15th April 2020 until 24th December 2020. MIAs were performed on the day of study inclusion (Fig. 4). A maximum of 2 MIAs were performed per day.

Informed consent and ethical approval 
Formally, no informed consent (IC) is needed for autopsy to be performed in tertiary and academic centres in Belgium. Nevertheless, we sought IC from the legal representative. Because of visiting restrictions in the hospital during the COVID-19 outbreak, most often the legal representative was contacted by phone by a study team member, who explained the study and asked oral IC. If consent was granted, the study information sheet was sent by registered mail. All patients were included after oral informed consent from the legal representative. The study received ethical approval from the Ethics Committee of Jessa hospital and Hasselt University (20.36-infecti20.05). All procedures performed in studies involving human participants were in accordance with the ethical standards of the institutional and national research committee and with the 1964 Helsinki Declaration and its later amendments or comparable ethical standards. Clinicaltrials.gov identifier: NCT 04366882.

MIA procedure

A full body CT-scan was performed in a 128-slice CT scanner (Somatom go.top; Siemens Healthcare, Erlangen, Germany) with the body in supine position. Volumetric scans were obtained from the vertex to the symphysis pubis at $120 \mathrm{kV}$ with variable $\mathrm{mAs}$, without intravenous or intra-arterial contrast. Image reconstruction with a soft tissue algorithm provided $3 \mathrm{~mm}$ slices, which were viewed on standard window settings for soft tissue, lung and bone.

Tissue biopsies were taken with the 'cutting needle alone' technique, using a 14G biopsy needle (Bard ${ }^{\circledR}$ Mission $^{\text {TM }}$ Disposable Core Biopsy Instrument; C.R. Bard, Inc., Tempe, AZ, USA). Four lung biopsies were collected for microbiological examination, at least 4 biopsies of each lung (2 biopsies radiologically normal and 2 biopsies radiologically abnormal) for histopathological examination and at least 2 biopsies from heart, kidney, liver, spleen, and abdominal fat for histopathological examination. Blood $(15 \mathrm{ml})$ was collected from the aorta in serum, lithium heparin and citrate tubes (Vacuette, Greiner-Bio, Vilvoorde, Belgium). Additional tissue and blood were collected for biobank storage at University Biobank Limburg (UBiLim) at $-80^{\circ} \mathrm{C}$.

Microbiology

Samples for microbiological examination were cultured in a level 3 safety lab. Lung tissue was inoculated on standard culture media for bacteria, yeasts and fungi and microorganisms were identified by Matrix-assisted laser desorption ionization-time of flight mass spectrometry. For all radiologically confirmed COVID-19 patients, we performed an in-house respiratory PCR panel on lung tissue on Quantstudio 7 flex (ThermoFisher) for the simultaneous detection of 23 respiratory pathogens, including SARS-CoV-2, influenza, RSV, adenovirus, enterovirus, human metapneumovirus, parainfluenza, rhinovirus, Bordetella holmesii, Bordetella pertussis, Bordetella parapertussis, Chlamydophila pneumoniae, Legionella pneumophila, and Mycoplasma pneumoniae.

Histopathology 
Samples for histopathological examination were stored in $10 \%$ neutral buffered formalin for 72 hours and embedded in paraffin. Haematoxylin and eosin staining was performed on all specimens. At least one lung biopsy per patient was stained with both CD3 immunohistochemical and elastin histochemical stains to assess the severity of lung disease. Additional stains were performed (CD4, CD8, Congo Red, elastine von Gieson, other) when deemed indicated by the pathologist.

Immunological analyses

The LegendPlex Human Anti-Virus Response Panel (13-plex) (740390, BioLegend) was used according to the manufacturer's instructions with minor adjustments. The assay was carried out in V-bottom 96-well plates and serum $(12.5 \mu \mathrm{L})$ was thawed and diluted twofold with assay buffer before testing. Standards, mixed beads, detection antibodies and streptavidin-PE were prepared according to the manufacturer's instructions and $12.5 \mu \mathrm{L}$ of each reagent was used. All serum samples were tested in duplicate. Data were collected using a LSRFortessa flow cytometer (BD Biosciences) and analysed using the LEGENDplex ${ }^{\text {TM }}$ Data Analysis Software Suite (BioLegend). Means of detection limits of duplicate tests were calculated and were used as a reference for cytokine levels under the detection limit. Antibodies against the receptor binding domain (RBD) in the S1 subunit of the SARS-CoV-2 S-protein, and IgG antibodies against the S1 subunit of the SARS-CoV-2 S-protein, were detected in serum or plasma samples using enzyme linked immunosorbent assays (ELISA) (IgM, Beijing Wantai Biological; IgG, Euroimmun), according to the manufacturer's instructions. Samples were considered seropositive according to the cut-off of the respective ELISA kits. IgG and IgM antibody levels were quantified by linear interpolation using serial dilutions of a positive plasma sample, which was later converted to arbitrary units (AU)/mL using the Anti-SARS-CoV-2 Antibody Diagnostic Calibrant (20/162) from the National Institute for Biological Standards and Control (NIBSC). Samples were measured twice independently, and the coefficient of variation of the average $\mathrm{AU} / \mathrm{ml}$ was lower than $30 \%$ for seropositive samples.

Data collection

The deceased patients' electronic medical file was assessed by at least one clinician who summarized medical history, discharge letters, file notes, and pre-mortem laboratory and radiological assessments. The post-mortem CT-scans were assessed by at least one radiologist following a standardized protocol. Pneumonias were classified as typical, indeterminate, atypical and normal according to the Radiological Society of North America classification ${ }^{25}$. The post-mortem lung cultures were assessed by a microbiologist. Culture results were scored as pathogen or contaminant/colonization based on identification and quantity. The histology slides were reviewed by four independent pathologists who subsequently discussed the findings of each organ and provided one conclusive finding based on consensus. The stages of DAD were scored according to hyaline membranes, inflammatory infiltrate, extent of fibrosis and divided into three groups: early exudative phase, mid proliferative phase, and late/organizing phase ${ }^{26}$. Inflammation was scored as being absent, mild, moderate, or severe. The composition of inflammatory infiltrates was assessed by scoring certain inflammatory cells as being absent, scarce, moderate, or numerous in number. 
Each patient was discussed during multidisciplinary meetings with at least one clinician, one radiologist, one pathologist, and one microbiologist. During the meeting a summary of the medical chart, the postmortem CT-images, the microbiological and histopathological findings were presented. Then, the participants discussed the results and defined the COD and contributing diagnoses based on consensus.

Statistical analyses

Patients were classified according to the WHO definitions of mild-moderate or severe-critical COVID disease at the moment of death ${ }^{27}$. Patients with a symptom onset of 28 days or more, were classified as post-acute COVID-19. If the moment of symptom onset was unavailable, the moment of positive PCRtesting was used. Comparison was made between mild-moderate disease, severe-critical disease, and post-acute COVID-19. Data are presented as number (percentage) for categorical data or median (IQR) for continuous data. Mann Whitney U test (continuous) or Chi-square test (categorical data) were used. A pvalue $<0.05$ was considered significant. All analyses were done using SPSS (version 25, IBM).

\section{Declarations}

\section{Acknowledgements}

The human biological material used in this publication was stored in and released from the University Biobank Limburg (UBiLim). Linsen L, Vanhees K, Vanoppen E, Ulenaers K, Driessens S, Penders J, et al. Raising to the Challenge: Building a Federated Biobank to Accelerate Translational Research-The University Biobank Limburg. Front Med (Lausanne). 2019;6:224.

This study is part of the Limburg Clinical Research Center (LCRC) UHasselt-ZOL-Jessa, supported by the foundation Limburg Sterk Merk (LSM), Hasselt University, Ziekenhuis Oost-Limburg, and Jessa Hospital.

\section{Author Contributions}

VD coordinated and executed the clinical cohort study and patient inclusion, collection, and analysis of the data, and wrote the manuscript L.K. and A.V did histopathological assessment of biopsies and analysis of pathological data. J.D., and ME.VdA did clinical chart review and multidisciplinary meetings. R.C. did microbiological review and multidisciplinary meetings, J.F. and P.V. did immunological and experimental work. V.S. supervised immunological experimental work and did critical review of the data. R.A., A.DD. and A.D. did histopathological assessment of biopsies multidisciplinary meetings laboratory work. L.A. performed autopsies and did radiological assessments. N.H. designed the immunological analysis plan, did analysis of the data, and did critical analysis of the manuscript. M.L. designed the histopathological analysis plan, did analysis of the data, and did critical analysis of the manuscript. J.V. performed autopsies, designed the radiological analysis plan, did analysis of the data, and did critical 
analysis of the manuscript. J.C. designed and coordinated the study and analysis, wrote, and did critical analysis of the manuscript. All authors read and approved the final manuscript.

\section{Funding}

This study has received funding from the Research Foundation Flanders (FWO) (G0G2620N).

\section{Conflict of interest}

The authors declare no competing interests.

\section{Data availability}

The datasets used and analysed during the current study are available from the corresponding author on reasonable request. The data are not publicly available due to them containing information that could compromise research participant privacy/consent.

\section{References}

1. Zhou F, Yu T, Du R, et al. Clinical course and risk factors for mortality of adult inpatients with COVID19 in Wuhan, China: a retrospective cohort study. The Lancet. 2020;395(10229):1054-1062. doi:10.1016/S0140-6736(20)30566-3

2. Wiersinga WJ, Rhodes A, Cheng AC, Peacock SJ, Prescott HC. Pathophysiology, Transmission, Diagnosis, and Treatment of Coronavirus Disease 2019 (COVID-19): A Review. Jama. Aug 25 2020;324(8):782-793. doi:10.1001/jama.2020.12839

3. Nalbandian A, Sehgal K, Gupta A, et al. Post-acute COVID-19 syndrome. Nat Med. Apr 2021;27(4):601-615. doi:10.1038/s41591-021-01283-z

4. Wu Z, McGoogan JM. Characteristics of and Important Lessons From the Coronavirus Disease 2019 (COVID-19) Outbreak in China: Summary of a Report of 72314 Cases From the Chinese Center for Disease Control and Prevention. Jama. Apr 7 2020;323(13):1239-1242. doi:10.1001/jama.2020.2648

5. van Halem K, Cox J, Messiaen P, et al. Care for adult non-ICU Covid-19 patients: early experiences from a Belgian tertiary care centre. Neth J Med. Apr 2020;78(3):111-115.

6. Carfi A, Bernabei R, Landi F. Persistent Symptoms in Patients After Acute COVID-19. Jama. Aug 11 2020;324(6):603-605. doi:10.1001/jama.2020.12603

7. Chopra V, Flanders SA, O'Malley M, Malani AN, Prescott HC. Sixty-Day Outcomes Among Patients Hospitalized With COVID-19. Ann Intern Med. 2021:576-578. vol. 4.

8. Gandhi RT. The Multidimensional Challenge of Treating COVID-19: Remdesivir is a Foot in the Door. Clin Infect Dis. Jul 31 2020;doi:10.1093/cid/ciaa1132

9. Giamarellos-Bourboulis EJ, Netea MG, Rovina N, et al. Complex Immune Dysregulation in COVID-19 Patients with Severe Respiratory Failure. Cell Host Microbe. Jun 10 2020;27(6):992-1000.e3. doi:10.1016/j.chom.2020.04.009 
10. Shields AM, Faustini SE, Kristunas CA, et al. Longitudinal protection following natural SARS-CoV-2 infection and early vaccine responses: insights from a cohort of community based dental health care professionals. medRxiv. 2021:2021.02.24.21252368. doi:10.1101/2021.02.24.21252368

11. Ackermann M, Verleden SE, Kuehnel M, et al. Pulmonary Vascular Endothelialitis, Thrombosis, and Angiogenesis in Covid-19. N Engl J Med. Jul 9 2020;383(2):120-128. doi:10.1056/NEJMoa2015432

12. Schurink B, Roos E, Radonic $T$, et al. Viral presence and immunopathology in patients with lethal COVID-19: a prospective autopsy cohort study. Lancet Microbe. Nov 2020;1(7):e290-e299. doi:10.1016/s2666-5247(20)30144-0

13. Laing AG, Lorenc A, Del Molino Del Barrio I, et al. A dynamic COVID-19 immune signature includes associations with poor prognosis. Nat Med. Oct 2020;26(10):1623-1635. doi:10.1038/s41591-0201038-6

14. Nienhold R, Ciani Y, Koelzer VH, et al. Two distinct immunopathological profiles in autopsy lungs of COVID-19. Nat Commun. Oct 8 2020;11(1):5086. doi:10.1038/s41467-020-18854-2

15. Huang $X$, Xiu H, Zhang S, Zhang G. The Role of Macrophages in the Pathogenesis of ALI/ARDS. Mediators Inflamm. 2018;2018:1264913. doi:10.1155/2018/1264913

16. Valdivia-Mazeyra MF, Salas C, Nieves-Alonso JM, et al. Increased number of pulmonary megakaryocytes in COVID-19 patients with diffuse alveolar damage: an autopsy study with clinical correlation and review of the literature. Virchows Arch. Mar 2021;478(3):487-496. doi:10.1007/s00428-020-02926-1

17. Wichmann D, Sperhake JP, Lütgehetmann M, et al. Autopsy Findings and Venous Thromboembolism in Patients With COVID-19: A Prospective Cohort Study. Ann Intern Med. Aug 18 2020;173(4):268277. doi:10.7326/m20-2003

18. Tal S, Spectre G, Kornowski R, Perl L. Venous Thromboembolism Complicated with COVID-19: What Do We Know So Far? Acta Haematol. 2020;143(5):417-424. doi:10.1159/000508233

19. D'Errico S, Zanon M, Montanaro M, et al. More than Pneumonia: Distinctive Features of SARS-Cov-2 Infection. From Autopsy Findings to Clinical Implications: A Systematic Review. Microorganisms. Oct 23 2020;8(11)doi:10.3390/microorganisms8111642

20. Hadjadj J, Yatim N, Barnabei L, et al. Impaired type I interferon activity and inflammatory responses in severe COVID-19 patients. Science. Aug 7 2020;369(6504):718-724. doi:10.1126/science.abc6027

21. Zhang Q, Bastard P, Liu Z, et al. Inborn errors of type I IFN immunity in patients with life-threatening COVID-19. Science. Oct 23 2020;370(6515)doi:10.1126/science.abd4570

22. Lansbury L, Lim B, Baskaran V, Lim WS. Co-infections in people with COVID-19: a systematic review and meta-analysis. J Infect. May 27 2020;doi:10.1016/j.jinf.2020.05.046

23. D'Onofrio V, Donders $E$, Vanden Abeele ME, et al. The clinical value of minimal invasive autopsy in COVID-19 patients. PLoS One. 2020;15(11):e0242300. doi:10.1371/journal.pone.0242300

24. Sciensano. COVID-19 Gevalsdefinitie. 2020. 
25. de Jaegere TMH, Krdzalic J, Fasen B, Kwee RM. Radiological Society of North America Chest CT Classification System for Reporting COVID-19 Pneumonia: Interobserver Variability and Correlation with Reverse-Transcription Polymerase Chain Reaction. Radiol Cardiothorac Imaging. Jun 2020;2(3):e200213. doi:10.1148/ryct.2020200213

26. Barisione E, Grillo F, Ball L, et al. Fibrotic progression and radiologic correlation in matched lung samples from COVID-19 post-mortems. Virchows Arch. Mar 2021;478(3):471-485. doi:10.1007/s00428-020-02934-1

27. World Health O. Clinical management of COVID-19: interim guidance, 27 May 2020. 2020. 2020. https://apps.who.int/iris/handle/10665/332196

\section{Figures}

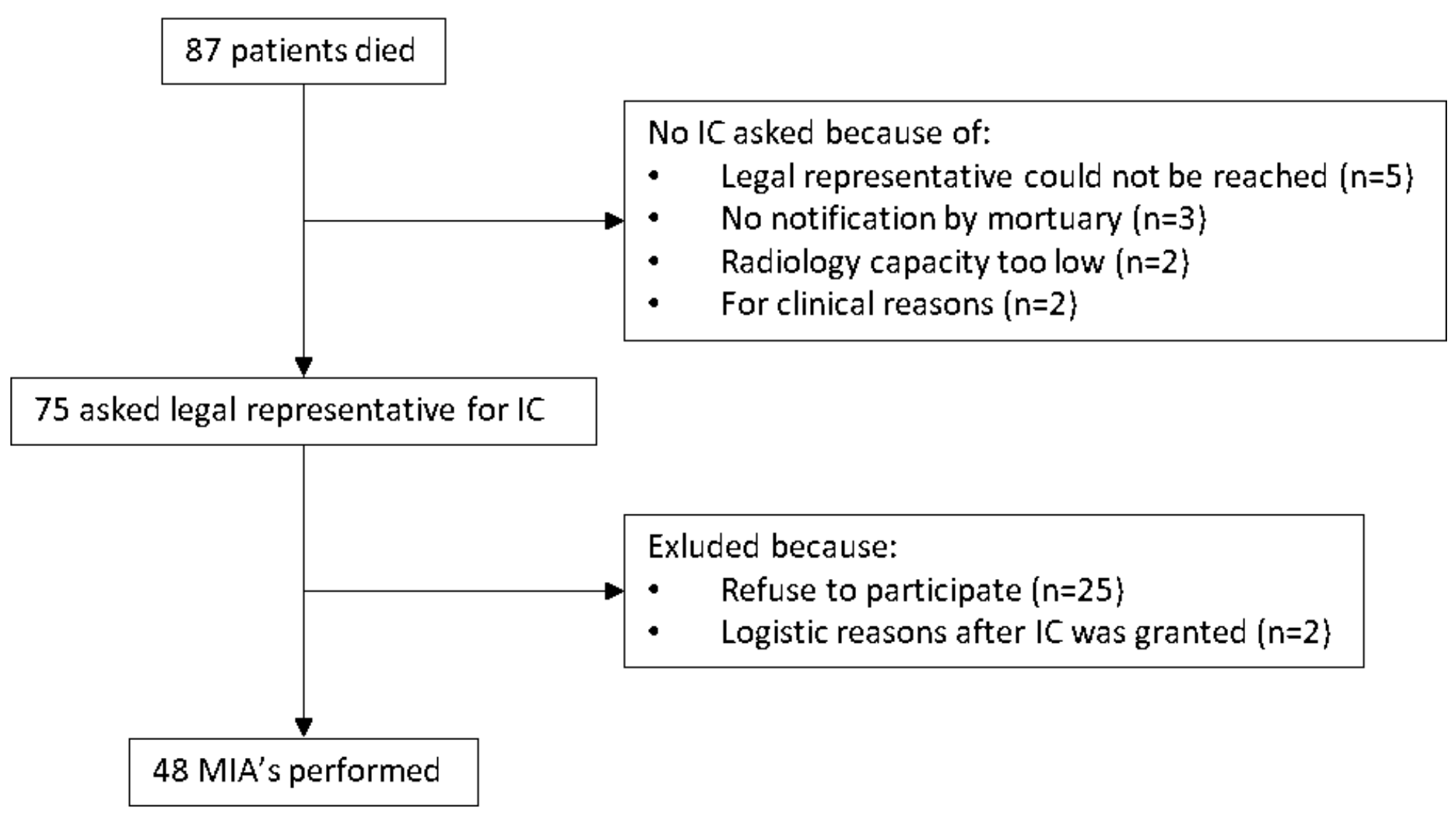

Figure 1

Flowchart of patient inclusions. 

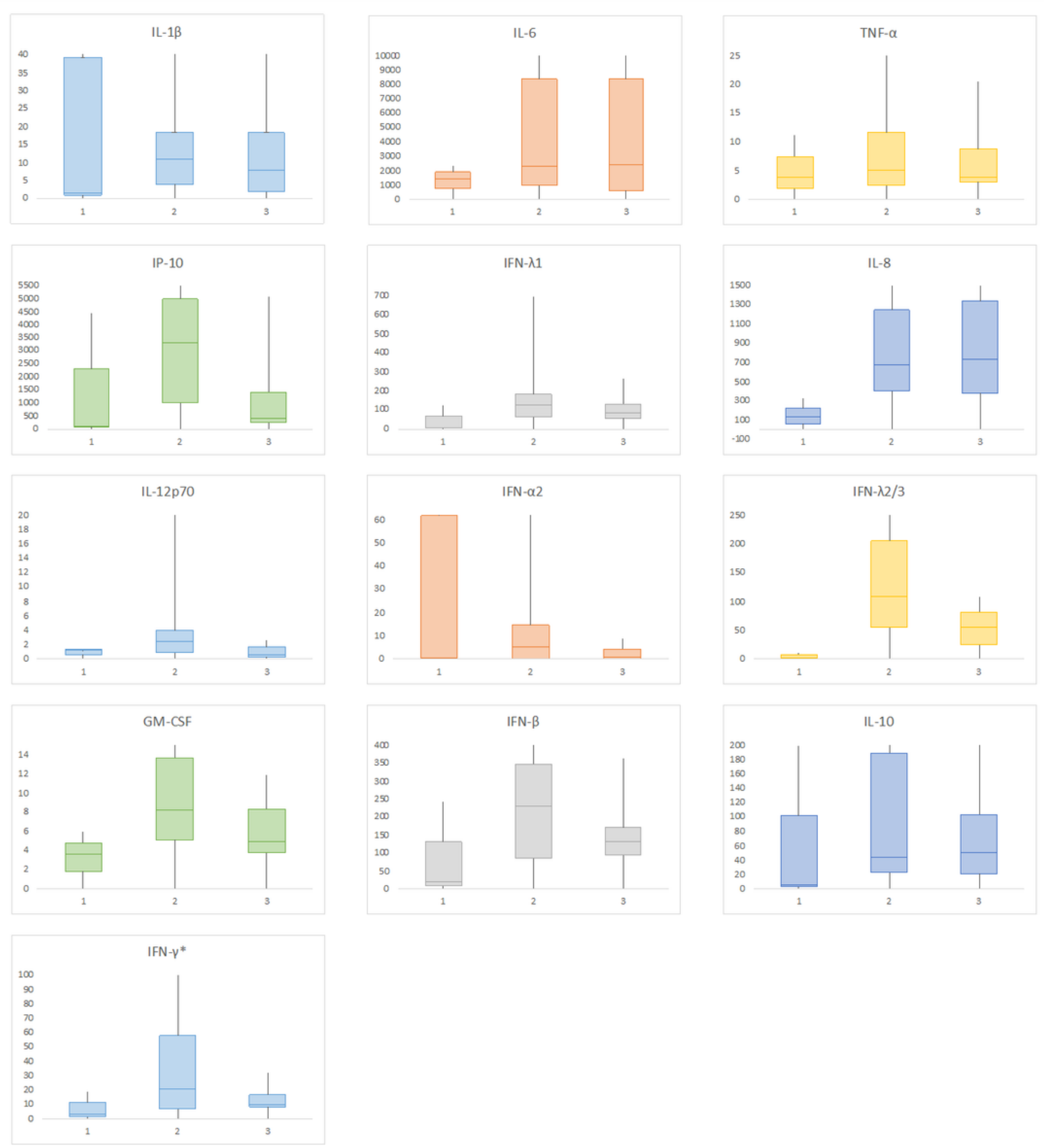

Figure 2

Postmortem cytokine levels in plasma per disease stage. 1: mild-moderate disease; 2: severe-critical disease; 3: post-acute disease. 


\begin{tabular}{|c|c|c|c|}
\hline N & Cinical Cause of Death & MA Cause of Death & $\mathbf{N}$ \\
\hline 30 & OOVID-19 severe pneumonia & OOVI-19 severe pneumonia & 22 \\
\hline 3 & Radidogical OOVI-19 severe pneumonia & Viral pneamonia & 2 \\
\hline 3 & Bacterial pneamnonia & Bacterial pneamonia & 3 \\
\hline $\mathbf{1}$ & Probable invasive Aspergitus fumigatus pulmonary infection & Heart failure & 6 \\
\hline $\mathbf{1}$ & Severe spondyloscitis with epichural absoess & Massive pulmanary embolism & $\mathbf{1}$ \\
\hline $\mathbf{1}$ & Aarte an OKF & Aarte on CKF due to cresoentic glomerulonephritis & $\mathbf{1}$ \\
\hline $\mathbf{1}$ & Hemmoraghic transformation of ischemic CVA & Hemmoraghic transformation of ischemic CVA & $\mathbf{1}$ \\
\hline $\mathbf{1}$ & Intraosebral bleeding & Intracerebral bleeding & $\mathbf{1}$ \\
\hline $\mathbf{1}$ & Intraocrebral bleeding with subdural hematoma & Intracerebral bleeding with subdural hematuma & $\mathbf{1}$ \\
\hline $\mathbf{1}$ & Para-tracheal bleeding ECI & Para-tracheal bleeding EC & $\mathbf{1}$ \\
\hline $\mathbf{1}$ & Fhabdamyolysis with subsequent MOF & Rhabdomyolysis with subsequent MOF & $\mathbf{1}$ \\
\hline $\mathbf{1}$ & MOF as a result of small intestine ischemia & Mof due to small intestine ischemia & $\mathbf{1}$ \\
\hline $\mathbf{1}$ & Small oell hung carinom a with metastasis & Small ofll lung carcinoma with metastasis & $\mathbf{1}$ \\
\hline \multirow[t]{5}{*}{$\mathbf{1}$} & Sudden death ECI & Sudden death ECI & $\mathbf{1}$ \\
\hline & & Bacterial pneumosepsis with septic shock & $\mathbf{1}$ \\
\hline & & Bacterial sepsis no dear focus & $\mathbf{1}$ \\
\hline & & Severe COPD & $\mathbf{1}$ \\
\hline & & Unknown & 1 \\
\hline
\end{tabular}

Figure 3

Clinical causes of death and changes to MIA cause of death.

Transfer of Deceased COVID-19 patient to mortuary

Informed consent from the legal representative

Transfer to radiology department

\section{Whole body CT scan \\ CT-guided biopsies}

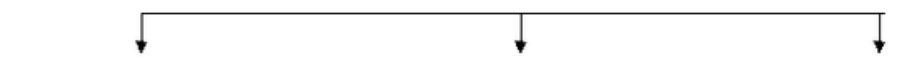

Tissue of lung

MDM:

Cause of death

Contributing diagnoses

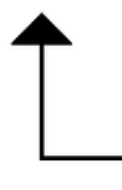

\section{Clinical data Protocol by synthesis radiologist}

Tissue of lungs, heart, liver, spleen, kidneys, abdominal fat

Figure 4 
Study Procedure. CT: computer tomography, MDM: multidisciplinary meeting.

\section{Supplementary Files}

This is a list of supplementary files associated with this preprint. Click to download.

- SupplementaryInformation02072021.docx 